\title{
LA ALTERNANCIA CAUSATIVA EN LOS VERBOS DE CAMBIO DE ESTADO FÍSICO DESDE LA PERSPECTIVA DE LA DESCOMPOSICIÓN DEL REFERENTE DEL SUJETO
}

\author{
Carlos Alonso Hidalgo Alfageme \\ Politechnika Śląska \\ http://dx.doi.org/10.18778/8220-201-4.02
}

\section{Resumen}

La alternancia causativa se ha explicado mediante la descomposición del evento y las nociones de causa y cambio. No obstante, las explicaciones generalmente aceptadas no dan cuenta de por qué algunos verbos de cambio de estado participan en la alternancia causativa (El niño crece / ${ }^{\star}$ Los padres crecen al niño) pero otros de significado muy parecido y con una estructura eventiva similar no lo hacen. ( $L a$ alimentación aumenta /Los padres aumentan la alimentación). Aquí se relacionará la alternancia causativa con otra descomposición: la del referente del sujeto en partes. Así, el diferente comportamiento de crecer y aumentar está relacionado con que el crecimiento de partes del niño, como la cabeza o los brazos, no implica que el niño crezca, mientras que el aumento de partes de la alimentación, como el pan o la fruta, implica que la alimentación aumenta.

Palabras clave: Alternancia causativa, causa, cambio de estado, inacusativo, anticausativo. 


\section{El problema}

La definición de la alternancia causativa está sujeta a matización y a las condiciones que imponen diferentes marcos teóricos, si bien una definición ecuménica podría ser la siguiente: La alternancia causativa es la variación que se establece entre una construcción inacusativa con un solo argumento (La presión se incrementa) y su contrapartida transitiva con dos argumentos, donde el argumento externo es la causa (El calor incrementa la presión). La construcción monoactancial se suele denominar incoativa o anticausativa; la construcción biactancial, transitiva o causativa. El problema que se va a tratar aquí es por qué unos verbos de cambio de estado físico participan en la alternancia causativa y otros, no. Ilustran el problema los siguientes pares de verbos. El primer verbo de cada par participa en la alternancia causativa; el segundo, no: aumentar y crecer, sumergirse y emerger, enfermar y resfriarse.

Las dos construcciones que intervienen en la alternancia causativa están evidentemente relacionadas, el debate se centra en establecer de qué modo; Van Valin (2013: 71-72) recopila cinco, en los que la noción de causa ocupa una posición central. Se acepta generalmente que en la representación léxica de los verbos que participan en la alternancia causativa están codificados dos eventos: un proceso y un estado. La versión anticausativa se deriva de la causativa mediante un proceso de ligamiento léxico del argumento $x$ del predicado del proceso ([x ACT $<$ MANNER $>$ ) (Levin, Rappaport Hovav, 1995). En la versión intransitiva el objeto afectado promociona o se mueve a la posición de sujeto, a la vez que un clítico pronominal absorbe el papel temático externo impidiendo que el verbo asigne caso acusativo a su único argumento (Grimshaw, 1982; Marantz, 1984; Wehrli, 1986; Cinque, 1988).

En español participan en la variante intransitiva de la alternancia causativa tan solo verbos inacusativos con se anticausativo (Mendikoetxea, 1999) (La ropa se seca / El sol seca la ropa). La participación de verbos sin se (Los impuestos aumentan / El gobierno aumenta los impuestos) da lugar a alternancias que no son 
propiamente causativas, conocidas también como pseudocausativas, porque el argumento que se omite no es una causa, sino un agente (Zribi-Hertz, 1987). En la alternancia causativa participan solo verbos referidos a eventos cuya realización depende directamente de una causa externa (si El sol seca la ropa, el sol es una causa situada en el exterior de la ropa); no participan en ella los verbos referidos a eventos cuya realización depende de una causa interna (como la causa de florecer en El árbol florece) (Levin, Rappaport Hovav, 1995; Mendikoetxea, 1999).

Sin embargo, la explicación de la alternancia entre una estructura intransitiva monoactancial y una estructura transitiva biactancial basada en la noción de causa presenta carencias a la hora de responder a cuestiones como las siguientes.

Si girar denota un proceso, y no el proceso más el estado que caracteriza a los verbos de cambio de estado, entonces, ¿ipor qué girar participa en la alternancia (pseudo)causativa: La ruleta gira / El concursante gira la ruleta?

¿Por qué sumergir participa en la alternancia (El cocodrilo se sumerge / El cocodrilo sumerge la presa) pero emerger, no (El cocodrilo emerge $/{ }^{\star}$ El cocodrilo emerge la presa)? ¿Cómo es posible que el primer verbo denote un evento de causa externa pero el segundo lo denote de causa interna? ¿Acaso no es el mismo cocodrilo el que hace que la presa emerja o se sumerja?

¿Por qué aumentar participa en la alternancia (La población aumenta / La inmigración aumenta la población), pero crecer, no (La población crece / ${ }^{*}$ La inmigración crece la población)? ¿Realmente se debe este comportamiento a la diferenciación entre la causa externa de aumentar y la causa interna de crecer? En el caso de aumentar, la ausencia del se invita a descartar que la noción de causa influya en una alternancia que no es causativa propiamente dicha. En el caso de crecer el evento podría estar sujeto a causas externas, como sugieren las oraciones La planta crece gracias al sol y El calcio hace crecer al niño, si bien es cierto que estas causas no pueden cumplir la función de sujeto de crecer.

¿Por qué resfriarse no participa en la alternancia (El deportista se resfria $/{ }^{*}$ La corriente resfría al deportista) pero enfermar sí lo hace (El deportista enferma / La corriente, la hipocresía enferma al 
deportista)? ¿No debería ser al revés, ya que resfriarse se construye con $s e$ ?

Estas preguntas revelan las paradojas inherentes a la introducción de la noción de causa en el análisis de la alternancia que nos ocupa. A continuación se abordará la alternancia desde un punto de vista que prescinde de la noción de causa. La hipótesis que se va a defender en los apartados siguientes consiste en que el análisis de la relación entre el referente del sujeto y sus partes permite prever qué verbos participarán en la alternancia causativa.

\section{2. \\ Bases teóricas de una explicación alternativa}

Las bases teóricas de la explicación alternativa de la alternancia causativa que se propondrá más abajo son dos: la herencia léxica y la descomposición de la unidad léxica. Seguidamente se presen$\tan$ ambas.

Por lo que respecta a la herencia léxica, sea la tipología semántica animal, mamífero, felino, gato. La herencia léxica consiste en el trasvase de características en la dirección de padres a hijos en el árbol que define la tipología semántica propuesta. Por ejemplo, si el tipo animal presenta las características respirar y desplazarse, entonces los subtipos mamífero y felino también presentarán las mismas características: las heredan. La herencia léxica comenzó a aplicarse en el campo de la inteligencia artificial (Roberts, Goldstein, 1977; Bobrow, Winograd, 1977) y en su desarrollo lingüístico se transmiste por esquemas arbóreos cuyos nodos son típicamente sustantivos (Carpenter, 1992; Copestake, 1992: 90). En desarrollos más modernos los nodos pueden ser también verbos: andar y correr son hijos que heredan características del padre mover (Amaro, 2006: 14).

En lo tocante a la segunda base teórica, el significado de la unidad léxica no es monolítico, sino que se puede descomponer. Pustejovsky (1995) toma como referente los aitiae (causas) de la 
Metafísica de Aristóteles para proponer la descomposición de las unidades léxicas en cuatro qualia (sing. quale) o roles: constitutivo, formal, agentivo y télico. El rol constitutivo, que es el que nos interesa ahora, recoge la información referente a la relación entre el objeto y sus partes o constituyentes. De este modo, dada la unidad léxica gato, su rol constitutivo codificaría el árbol patas, pezuñas, uñas.

Al sumar la tipología semántica más el rol constitutivo del objeto gato, resulta una estructura en la que ese objeto ocupa una posición central: animal, mamífero, felino, GATO, patas, pezuñas, uñas. En la parte superior de la estructura, la tipología semántica define los conjuntos a los que pertenece el objeto; la herencia léxica es la transmisión de información entre esos conjuntos. En la parte inferior de la estructura no opera la herencia léxica. La trasmisión de información entre el objeto y sus partes se produce por medio de lo que vamos a denominar herencia del evento. La herencia del evento se define en (1):

(1) a. Definición de herencia de un evento: La herencia de un evento es la transmisión de la participación en ese evento entre un objeto y al menos una de sus partes. El verbo que predica de un objeto puede hacerlo también de sus partes. Por ejemplo, si Una fábrica humea, entonces también se puede afirmar que Su chimenea humea.

b. Sentido de la herencia de un evento. La transmisión de la participación en el evento puede producirse en dos sentidos: bien de las partes al objeto o bien del objeto a las partes. La trasmisión en el sentido parte-objeto se aprecia en el ejemplo Si el bíceps del atleta se fortalece, entonces el atleta se fortalece. La trasmisión en el sentido objeto-parte se aprecia en el ejemplo Si una representación termina, entonces su último acto termina.

La importancia de la herencia del evento radica en que es el mecanismo que articula la alternancia entre una construcción intransitiva y otra transitiva independientemente de la noción de causa, como se va a tratar de mostrar a continuación. 


\section{Presentación de una explicación alternativa}

En (2) se proponen dos diagnósticos. El diagnóstico de (a) comprueba si la herencia del evento se produce en el sentido objeto-parte; el diagnóstico de (b) comprueba si se produce en el sentido parte-objeto. Dado que la herencia se trasmite durante el transcurso de un evento y no depende del resultado final, en los diagnósticos se emplea la perífrasis progresiva estar + gerundio.

(2) Girar. La ruleta gira / El concursante gira la ruleta.

a. Mientras la ruleta está girando, \{el eje / los números / los colores / el borde\} está(n) girando.

b. Mientras \{el eje / los números / los colores / el borde\} está(n) girando, la ruleta está girando.

En (2), lo que girar predica del objeto (ruleta) lo puede predicar también de cualquiera de sus partes, y viceversa. Por ejemplo, si la ruleta gira, es posible predicar de su borde que gira también (2a); y viceversa: si su borde gira, entonces la ruleta hace lo mismo (2b). El verbo girar permite tanto que cualquiera de las partes herede del objeto ruleta la participación en el evento (2a) como que el objeto herede esa participación de cualquiera de sus partes (2b). Paralelamente se comprueba que el verbo girar participa en la alternancia causativa (2). La relación entre la herencia del evento en los dos sentidos y la alternancia que nos ocupa no parece ser una relación de causa-efecto, simplemente ambos fenómenos aparecen asociados.

A continuación se aplican los mismos diagnósticos de la herencia a los sinónimos parciales aumentar (3) y crecer (4).

(3) Aumentar. La población aumenta. / La inmigración aumenta la población.

a. Mientras la población está aumentando, \{los hombres / las mujeres / los jóvenes / los viejos\} están aumentando.

b. Mientras \{los hombres/las mujeres/los jóvenes/los viejos\} están aumentando, la población está aumentando. 
(4) Crecer. Pinocho crece. / * La comida crece a Pinocho.

a. Mientras Pinocho está creciendo, \{sus piernas / su tronco / su nariz / sus uñas\} está(n) creciendo.

b. Mientras \{sus piernas / su tronco / *su nariz / *sus uñas\} está(n) creciendo, Pinocho está creciendo.

En (3), con el verbo aumentar, el evento en el que participa el objeto (la población) puede predicarse también de cualquiera de sus partes (los hombres, las mujeres, los jóvenes, los viejos) (3a). Y viceversa: si en el evento aumentar participa cualquiera de las partes de la población, se puede predicar de la población que aumenta (3b). La transmisión de la participación en el evento aumentar en los dos sentidos aparece asociada con la alternancia causativa (3). En contraste, cuando el verbo es crecer la herencia no se produce en un sentido. En concreto, si la nariz de Pinocho crece, no se puede afirmar que Pinocho crezca también. Pinocho tampoco crece si lo hacen sus uñas, su pelo e incluso sus músculos si los ejercita (4b). Se comprueba que el verbo crecer no participa en la alternancia causativa (4).

Las explicaciones al uso de la alternancia causativa tampoco explican su distribución en la pareja de antónimos sumergirse y emerger.

(5) Sumergirse. El submarino se sumerge. / El capitán sumerge el submarino.

a. Mientras el submarino se está sumergiendo, su \{hélice / torreta / proa / popa\} se está sumergiendo.

b. Mientras su \{hélice / torreta / proa / popa\} se está sumergiendo, el submarino se está sumergiendo.

(6) Emerger. El submarino emerge. / *El capitán emerge el submarino.

a. Mientras el submarino está emergiendo, su \{\#hélice / torreta /\#proa /\#popa\} está emergiendo.

b. Mientras su \{hélice/torreta / proa / popa\} está emergiendo, el submarino está emergiendo. 
Sumergirse significa "meter algo debajo del agua o de otro líquido" en la primera acepción del DLE y "abismar, hundir", en la segunda acepción. Durante el transcurso del evento sumergirse, la hélice se hunde más en el abismo, la torreta se mete debajo del agua y todas las demás partes del submarino participan en el evento sumergirse en una o en la otra acepción. Si el submarino se sumerge, sus partes heredan el evento y se sumergen también (5a); si son las partes las que se sumergen, el mismo verbo puede predicar también de todo el submarino (5b). Se comprueba que el verbo sumergirse participa en la alternancia causativa (5).

Emerger en su única acepción del DLE significa brotar, salir a la superficie del agua u otro líquido. La hélice no emerge cuando lo hace el submarino (6a). Pueden permanecer sumergidas también la proa y la popa cuando el submarino emerge. Por tanto, el submarino no trasmite su participación en el evento emerger a todas las partes que pueden emerger, lo que se traduce en que este verbo no participa en la alternancia causativa (6).

La última pareja problemática a la que se aplicarán los diagnósticos propuestos son los sinónimos parciales resfriarse y enfermar.

(7) Resfriarse. El deportista se resfría. / *La corriente resfría al deportista.

a. Mientras el deportista se está resfriando, \{'sus pulmones / *su nariz / *su hígado / *sus piernas\} se está(n) resfriando.

b. Mientras \{ ${ }^{*}$ sus pulmones / *su nariz / *su hígado / *sus piernas\} se está(n) resfriando, el deportista se está resfriando.

(8) Enfermar. El deportista enferma. / La corriente enferma al deportista.

a. Mientras el deportista está enfermando, \{sus pulmones / su nariz / su hígado / sus piernas\} está(n) enfermando.

b. Mientras \{sus pulmones / su nariz / su hígado / sus piernas\} está(n) enfermando, el deportista está enfermando. 
La extrañísima particuladidad de resfriarse es que no participa en la alternancia causativa a pesar de ser un verbo de cambio de estado pronominal con se. Acerca del se de este verbo, es necesario señalar que se comporta a todas luces como anticausativo desde el momento en que impide la aparición de un argumento causa o agente en la oración. No es un se inherente, ya que el $D L E$ recoge la versión no pronominal de resfriar. Tampoco es un se aspectual, porque no es optativo. De este modo, resfriarse contravendría la regla de que todos los verbos con se anticausativo participan en la alternancia causativa (Mendikoetxea, 1999).

En cualquier caso, es posible explicar la diferente participación en la alternancia (pseudo)causativa de resfriarse y de enfermar dejando a un lado la naturaleza de ese se y el concepto de causatividad. Atendiendo al análisis propuesto de la herencia del evento, la principal diferencia entre resfriarse y enfermar estriba en que las partes del referente del sujeto no pueden resfriarse (7a-b), pero pueden enfermar (8a-b). Y viceversa: si cualquier órgano enferma, es posible predicar de la persona que enferma (8b), pero no que se resfría (7b). La herencia del evento enfermar aparece asociada con la alternancia que nos ocupa (8), que sería causativa propiamente dicha si se tiene en cuenta que, sobre todo en América, enfermar se usa como verbo pronominal (enfermarse). En España este verbo no suele llevar marca de diátesis, por lo que se da la circunstancia de que un verbo diatéticamente neutro (enfermar) tolera la alternancia causativa, mientras que un sinónimo parcial pronominal (resfriarse), no lo hace.

\section{4.}

\section{Conclusiones}

Los datos de (2-8) muestran una relación entre la alternancia causativa y la herencia del evento en sus dos sentidos. La observación de estos datos lleva a formular la hipótesis de (9).

(9) Un verbo intransitivo participa en la alternancia causativa si se cumplen dos condiciones: 
a. si el evento que se predica del sujeto se puede predicar también de alguna de las partes de su referente (Si el operario ensordece, entonces sus oídos ensordecen), y

b. si el evento que se predica de las partes del referente del sujeto se puede predicar también del sujeto (Si sus oídos ensordecen, entonces el operario ensordece). 0 , lo que es lo mismo,

c. si la herencia del evento se trasmite en la dirección todo-parte.

d. si la herencia del evento se trasmite también en la dirección parte-todo.

\section{Referencias bibliográficas}

Amaro, R. (2006), "WordNet as a Base Lexicon Model for the Computation of Verbal Predicates", en P. Sojka, K-S. Choi, C. Fellbaum y P. Vossen (eds.), GWC Proceedings, Brno: Masarykova Univerzita, 9-17.

Aristóteles (1978), Metafísica, Buenos Aires: Editorial Sudamericana.

Bobrow D. G. y Winograd, T. A. (1977), "An overview of KRL, a knowledge representation language", Cognitive Science, 1, 3-46.

Carpenter, B. (1992), The Logic of Typed Feature Structures, Cambridge: Cambridge University Press.

Cinque, G. (1988), "On si constructions and the theory of Arb", Linguistic Inquiry, 19 (4), 521-581.

Copestake, A. (1992), "The ACQUILEX LKB: representation issues in semi-automatic acquisition of large lexicons", Proceedings of the 3rd Conference on Applied Natural Language Processing, Stroudsburg: Association for Computational Linguistics, 88-95.

Grimshaw, J. (1982), “On the Lexical Representation of Romance Reflexive Clitics”, en J. Bresnan (ed.), The Mental Representation of Grammatical Relations, Cambridge: MIT Press, 87-148.

Levin, B. y Rappaport Hovav, M. (1995), Unaccusativity: At the syntax-semantics interface, Cambridge: MIT Press. 
Marantz, A. (1984), On the nature of grammatical relations, Cambridge: MIT Press.

Mendikoetxea, A. (1999), "Construcciones inacusativas y pasivas”, en I. Bosque y V. Demonte (eds.), Gramática descriptiva de la lengua española, Vol. 2, Las construcciones sintácticas fundamentales, Madrid: Espasa Calpe, 1575-1629.

Pustejovsky, J. (1995), The generative lexicon, Cambridge: MIT Press.

Real Academia Española (2014), Diccionario de la lengua española (DLE), Barcelona: Espasa [vigesimotercera edición].

Roberts, B. y Goldstein I. (1977), The FRL Manual. Technical Report. MIT AI Memo 409, Cambridge: MIT Artificial Intelligence Laboratory.

Van Valin, R. D. (2013), "Lexical Representation, Co-composition, and Linking Syntax and Semantics", en J. Pustejovsky, P. Bouillon, H. Isahara, K. Kanzaki y C. Lee (eds.), Advances in Generative Lexicon Theory, Dordrecht: Springer, 67-107.

Wehrli, E. (1986), “On some Properties of French Clitic Se”, en H. Borer (ed.), The Syntax of Pronominal Clitics, San Francisco: Academic Press, 263-283.

Zribi-Hertz, A. (1987), "La réfléxivité ergative en français moderne”, Le Français moderne 55, 23-54. 